\title{
Stress analysis in a bone fracture fixed with topology-optimised plates
}

\author{
Abdulsalam Abdulaziz Al-Tamimi ${ }^{1,2} \cdot$ Carlos Quental $^{3} \cdot$ Joao Folgado $^{3} \cdot$ Chris Peach $^{2,4} \cdot$ Paulo Bartolo $^{2}$
}

Received: 10 July 2019 / Accepted: 9 October 2019 / Published online: 24 October 2019

(c) The Author(s) 2019

\begin{abstract}
The design of commercially available fixation plates and the materials used for their fabrication lead to the plates being stiffer than bone. Consequently, commercial plates are prone to induce bone stress shielding. In this study, three-dimensional fixation plates are designed using topology optimisation aiming to reduce the risk of bone stress shielding. Fixation plate designs were optimised by minimising the strain energy for three levels of volume reduction (i.e. $25 \%, 45 \%$ and $75 \%$ ). To evaluate stress shielding, changes in bone stress due to the different fixation plate designs were determined on the fracture plane of an idealised shaft of a long bone under a four-point bending load considering the effect of a patient walking with crutches of a transverse fractured tibia. Topology optimisation is a viable approach to design less stiff plates with adequate mechanical strength considering high volume reductions, which consequently increased the stress transferred to the bone fracture plane minimising bone stress shielding.
\end{abstract}

Keywords Fixation plates $\cdot$ Stress analysis $\cdot$ Stress shielding $\cdot$ Topology optimisation

\section{Introduction}

Stress shielding is an important phenomenon that must be considered during design optimisation of fracture fixation plates to minimise the risk of bone resorption and plate failure (Prasad et al. 2017). It is the result of the stiffness mismatch between the most commonly used metallic fracture fixation plates and bones (e.g. Young's modulus of $\mathrm{Ti}-6 \mathrm{Al}-4 \mathrm{~V}$ is around $120 \mathrm{GPa}$ and cortical bone is 15-25 GPa), which strongly determines the bone remodelling process whereby, according to Wolff's law, bone adapts to the forces acting upon it (Ridzwan et al. 2007; Elias et al.

Electronic supplementary material The online version of this article (https://doi.org/10.1007/s10237-019-01240-3) contains supplementary material, which is available to authorized users.

Paulo Bartolo

paulojorge.dasilvabartolo@manchester.ac.uk

1 Industrial Engineering Department, College of Engineering, Kind Saud University, Riyadh, Saudi Arabia

2 School of Mechanical, Aerospace and Civil Engineering, The University of Manchester, Manchester, UK

3 IDMEC, Instituto Superior Técnico, Universidade de Lisboa, Lisbon, Portugal

4 Manchester University NHS Foundation Trust, Manchester, UK
2008; Quental et al. 2014). This means that the load distribution in the bone-plate interface during healing will be uneven, mainly supported by the bone plate and screws. This will shield the bone from the stress stimulus required to provide adequate bone healing and eventually cause bone resorption and implant loosening, in a phenomenon known as "stress shielding" (Ridzwan et al. 2007; Prasad et al. 2017).

Stress shielding in bone is a common problem induced by mild- to high-load-bearing medical implants and can be reduced by redesigning the medical implant (Ramakrishna et al. 2004; Galbusera et al. 2009). The use of topology optimisation is gaining significant attention due to the ability to automatically generate optimal redesigns for a given design, considering different loading conditions and volume reduction constraints. Several authors demonstrated the feasibility of topology optimisation for the redesign of orthopaedic medical implants to minimise stress shielding such as femur hip joints (Ridzwan et al. 2006; Fraldi et al. 2010; Saravana and George 2017), spine (Chuah et al. 2010) and pelvic prostheses (Iqbal et al. 2019). In these cases, results showed improved load transfer to the bone in the case of optimised implants. Similarly, Liu et al. (2017) used topology optimisation to design mandible fixation plates with adequate biomechanical performance. The optimised designs obtained through topology optimisation present complex internal/porous structures 
difficult to produce using conventional manufacturing technologies (Iqbal et al. 2019). Additive technology is the ideal technique to produce these plates, not only due to the ability to produce very complex shapes, but also due to the fact that the use of additive manufacturing allows to reduce material waste, part fabrication without the use of complex tooling, being the ideal technology for mass personalisation (Parthasarathy 2015; Murr 2016). For metal fixation plates, the ideal additive manufacturing technologies are selective laser melting (SLM) and electron beam melting (EBM) (Calignano et al. 2019; Yuan et al. 2019).

A valid concern when reducing stiffness of implants is whether the change in biomechanical characteristics has a negative effect on the stability at the fracture site which might affect bone healing. In order to ensure appropriate stresses imposed on the bone, fixation plates' stiffness should be optimised whilst maintaining plate stability during the healing process.

Therefore, this paper, as the authors' best of knowledge, is the first study investigating the use of topology optimisation to design fixation plates that minimise stress shielding and promote load transfer to the bone fracture plane, thus stimulating bone remodelling. Two different fixation plates were considered (four- and eight-screw holes) and were optimised for different loading conditions (bending, compression, torsion and a combined load) and three volume reductions ( $25 \%, 45 \%$ and $75 \%$ ). The optimised plates were evaluated using finite element analyses considering a tibia-like bone shape model under a bending loading condition to study the induced stresses on the defined bone fracture plane.

\section{Modelling and simulation}

\subsection{Optimisation and mechanical evaluation}

The Solid Isotropic Microstructure with Penalisation (SIMP) method was applied to redesign two different fixation plates with four- and eight-screw holes. Initial designs were created in Solidworks (Dassault Systèmes, Waltham, MA, USA) considering generic locking compression fixation systems for treating long bones for midshaft fractures with a length of $180 \mathrm{~mm}$, width of $14 \mathrm{~mm}$ and thickness of $5 \mathrm{~mm}$. Three volume reductions $(25 \%, 45 \%$ and $75 \%)$, and different loading conditions (bending, compression, torsion and a combination of all these loads), were considered as shown in Fig. 1. A frozen region was considered on the screw hole region to keep their shape. Simulations were performed considering quadratic hexahedral meshes with around 50,000 elements.

Mathematically, the SIMP formulation can be described as follows (Bendsøe and Sigmund, 2004):

$\min _{\rho_{e}} C\left(\rho_{e}\right)=\mathbf{f}^{\mathrm{T}} \cdot \mathbf{u}$ subject to $\left\{\begin{array}{l}\sum_{e=1}^{N} \rho_{e} v_{e} \leq V^{*}, \\ \left(\sum_{e=1}^{N} \rho_{e}^{p} \mathbf{K}_{e}\right) \mathbf{u}=\mathbf{f}, \\ 0<\rho_{0} \leq \rho_{e} \leq 1,\end{array}\right.$

where $C$ is the compliance, $p$ is a penalisation factor $(p=3)$, $\mathbf{u}$ is the displacement vector, $\mathbf{f}$ is the force vector, $\rho_{e}$ is the element density, $\rho_{\mathrm{o}}$ is the initial density, $V^{*}$ is the volume fraction, $v_{e}$ is the volume of each element, and $\mathbf{K}_{e}$ is the element stiffness matrix. The topology optimisation problem was run using the TOSCA module in Abaqus (Dassault Systèmes, Waltham, MA, USA).

The mechanical behaviour of both initial and optimised designs was investigated through finite element analyses, assuming elastic behaviour and homogeneous and isotropic plates. Numerical simulation was used to determine the equivalent stiffness in a four-point bending setting according to the British standards (BS 3531-23.1:1991 ISO 9585:1990). In this case, the equivalent bending stiffness is determined according to the following equation:

$E_{\mathrm{B}}=\frac{\left(4 h^{2}+12 h a+a^{2}\right) \cdot K \cdot h}{24}\left(\mathrm{~N} \mathrm{~m}^{2}\right)$

where $h$ is the distance between the force points, $a$ is the span between the force and support points, and $K$ is the stiffness calculated as follows:

$K=\frac{\mathrm{RF}}{D}(\mathrm{~N} / \mathrm{m})$

where $\mathrm{RF}$ is the average reaction force in the $z$ axis (along with the fixation plate thickness) at the constraint points and $D$ is the maximum displacement.

Changes in the equivalent stiffness between the optimised fixation plates and the initial designs were calculated using the following equation:

$\Delta$ equivalent stiffness $(\%)$

$$
=\frac{\left(\text { Plate stiffness }^{\text {Optimised }}-\text { Plate stiffness }^{\text {Initial }}\right)}{\text { Plate stiffness }^{\text {Initial }}}
$$

\subsection{Stress analysis of a bone model}

In order to determine the stresses in the fracture plane of a bone, which provides an indication of the stress shielding effect of the plates, a bone-plate construct (i.e. the assembly of the fracture plate to the bone with screws) was considered. For simplicity, no fracture gap was imposed, and the plate was assumed to fixate a transverse fractured tibia bone. Only the cortical bone region was considered, 
Fig. 1 Load and boundary conditions considered for the fixation plate optimisation of a four-point bending load, b uniaxial compression, $\mathbf{c}$ torsional and $\mathbf{d}$ combination of the bending, compression and torsion loads

All displacement and rotation were assumed to be equal zero

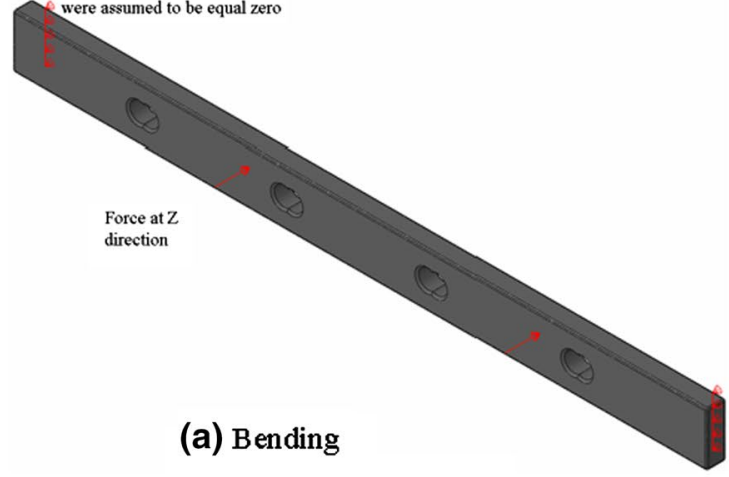<smiles>[Y]CC(C[Z])C[Y]</smiles>

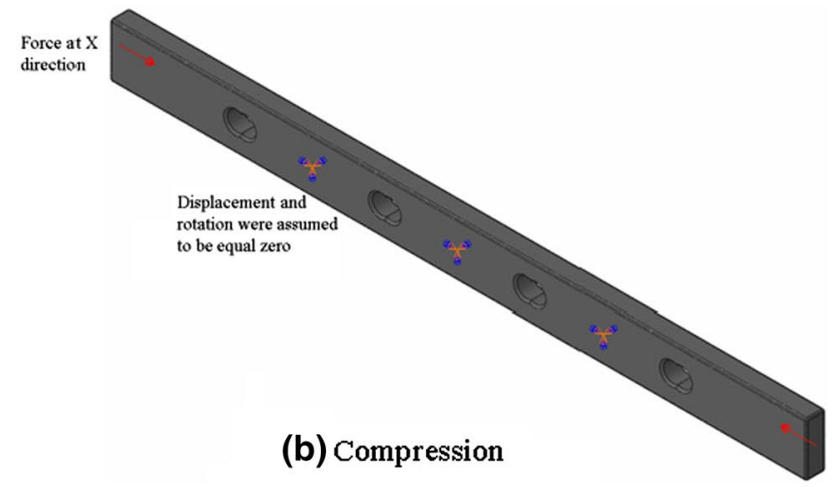

Moment around $\mathrm{X}$ direction
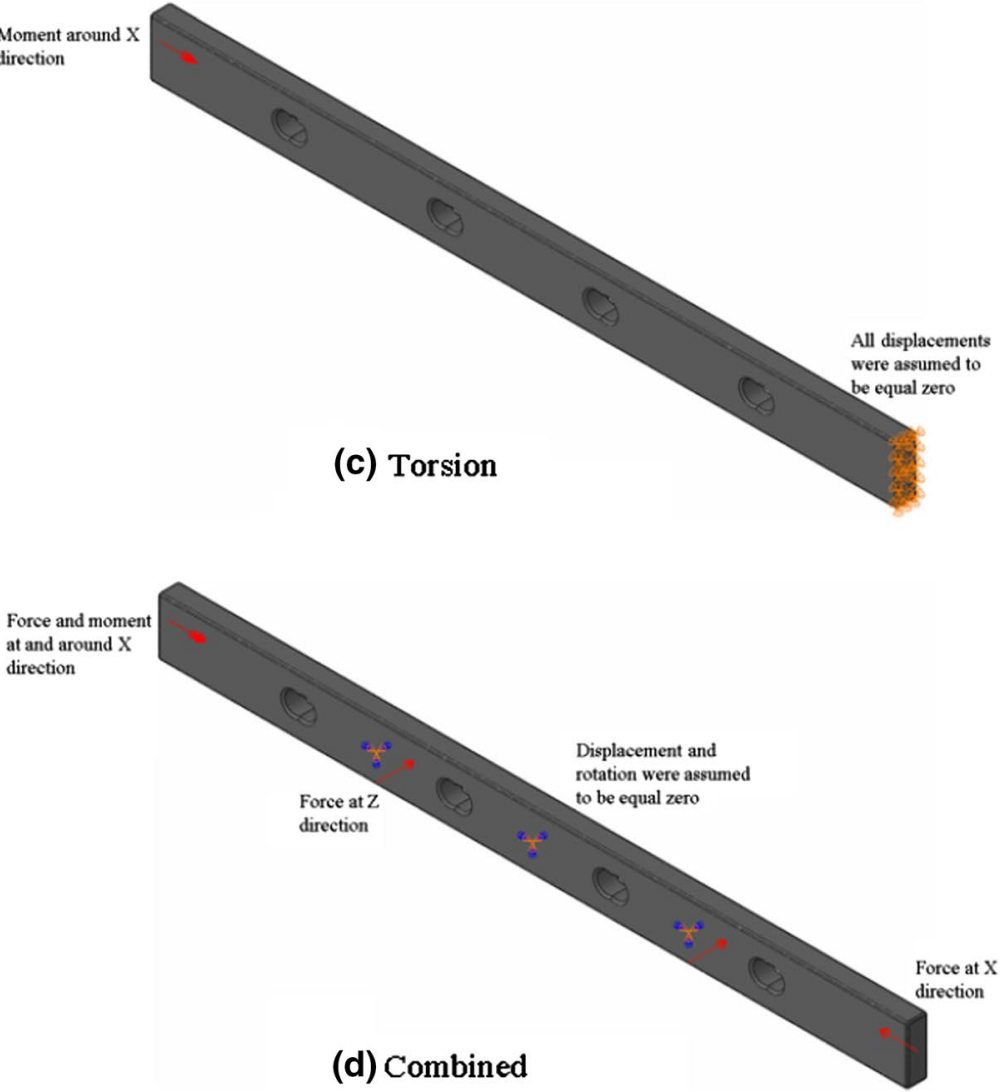
and a hollow cylinder region with an external diameter of $24 \mathrm{~mm}$ and an internal diameter of $12 \mathrm{~mm}$ was assumed for simulation purposes.

All 3D geometric parts, i.e. cortical bone, screws and initial fixation plates, were modelled in Solidworks (Dassault Systèmes, Waltham, MA, USA). Each screw has a 5-mmdiameter head and a main body with $3.5 \mathrm{~mm}$ of diameter and $34 \mathrm{~mm}$ of total length. Both fracture plates and screws were assumed to be made of Ti-6Al-4V. For the cortical bone, a Young's modulus of $18 \mathrm{GPa}$ and a Poisson's ratio of 0.3 were assumed (Santos et al. 2018). In order to avoid high computational costs, only half of the bone-plate construct was considered, as illustrated in Fig. 2. To simulate the Locking Compression Plate technique, the finite element model considered the bone-plate construct with a gap of $0.5 \mathrm{~mm}$ between the bone and plate (i.e. no contact). The screw heads were securely locked to the plate and the screws tied to the bone. Quadratic hexahedral elements were considered for the bone model region of interest (i.e. fracture plane) and quadratic tetrahedron elements for the plates, screws and the bone region outside of the fracture plane. Two equally distributed moments of $20 \mathrm{Nm}$ were applied along the horizontal axis of the bone, simulating the moment load happening on the tibia during the swing phase (i.e. $10 \%$ of the body weight) in patients walking with crutches (Ramakrishna et al. 2004; Wehner et al. 2009; Kim et al. 2011). To prevent rigid body motion, the extremity faces of the bone were fully constrained.

In addition, since the mechanical strength of the topologyoptimised fixation plates is important to assess their stability during healing, a mechanical strength analysis was performed based on the materials yield strength, considering the yield strength of the Ti-6Al-4V as $\sim 860 \mathrm{MPa}$ (Elias et al. 2008). The von Mises stresses on the topology-optimised fixation plates were used to determine their mechanical strength and, consequently, to investigate their stability.

\section{Results}

The changes in the equivalent stiffness between the optimised and initial designs are shown in Table 1. Optimised designs obtained through topology optimisation are presented as supplementary material (Figs. S1 and S2). The equivalent bending stiffness change increases as the volume reduction increases. For the same volume reduction and plates with different number of holes, there is no clear

Table 1 Change in the equivalent bending stiffness in comparison with the initial values for four- and eight-hole plates (19.27 and $16.22 \mathrm{~N} \mathrm{~m}^{2}$, respectively)

\begin{tabular}{llll}
\hline Plate & $\begin{array}{l}\text { Volume } \\
\text { reduction }(\%)\end{array}$ & \multicolumn{2}{l}{ Hole numbers } \\
\cline { 3 - 4 } & & \multicolumn{2}{l}{ Equivalent stiffness change (\%) } \\
\cline { 3 - 4 } & & Four-hole plate & Eight-hole plate \\
\hline Bending & 25 & -3 & -2 \\
& 45 & -5 & -5 \\
& 75 & -20 & -61 \\
Compression & 25 & -15 & -15 \\
& 45 & -17 & -28 \\
& 75 & -49 & -71 \\
Torsion & 25 & -9 & -31 \\
& 45 & -49 & -33 \\
Combined & 75 & -4 & -64 \\
& 25 & -57 & -4 \\
& 45 & -92 & -7 \\
\hline
\end{tabular}

Fig. 2 Bone-plate construct considered to determine stresses at the fracture plane

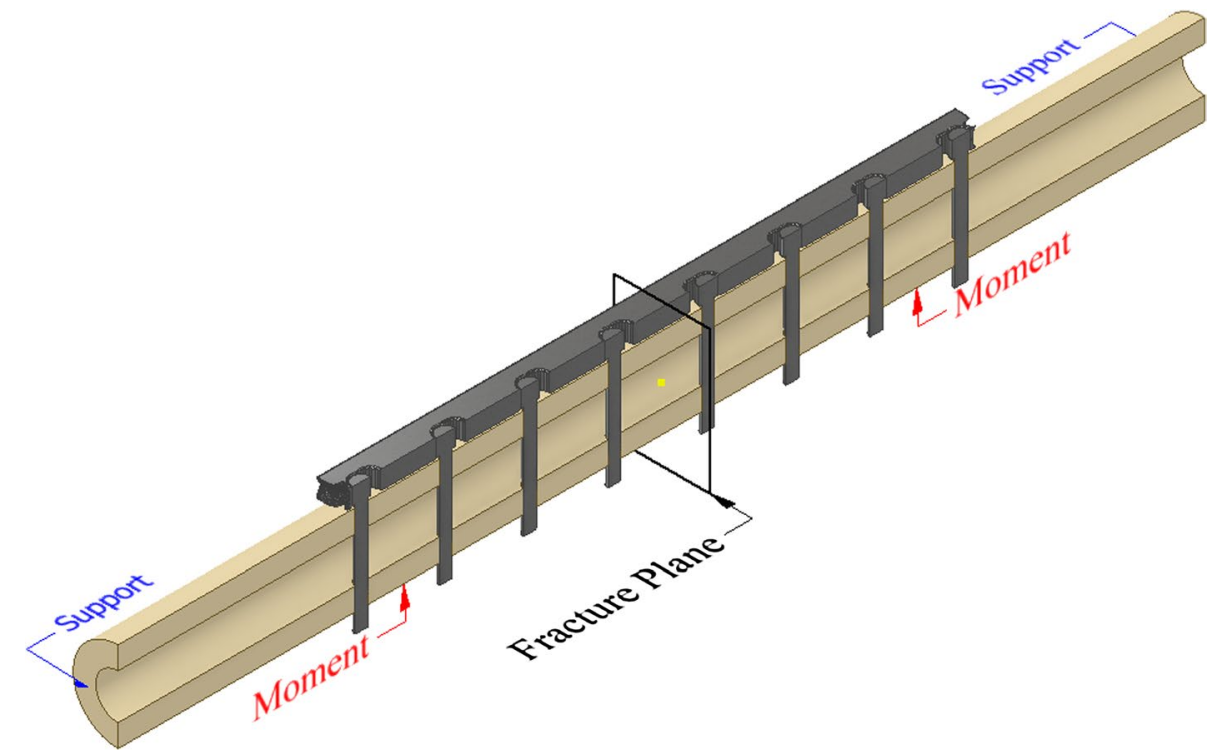


trend in terms of the equivalent stiffness change. Also, as expected, plates optimised considering bending loading conditions exhibit the least reduced equivalent stiffness change. The highest decreases were observed for the $75 \%$ volume reduction with combined load for the four-hole and eight-hole.

The maximum von Mises stresses from the bone-plate construct at the fracture plane, considering both the initial and topology-optimised fixation plates, are presented in Table 2. The stress distribution and magnitude at the bone fracture plane are presented in Fig. 3, for the initial designs and only for the $75 \%$ volume reduction optimised plates, which is the case causing the maximum von Mises stresses on the bone at the fracture plane. Overall, the stresses in the bone increase when topology-optimised plates are used. The most substantial increase in stresses at the fracture plane was observed for the combined loading conditions and $75 \%$ volume reduction plates. In comparison with the initial designs, the maximum stresses at the fracture plane increased by $31 \%$ for the four-hole plate and $37 \%$ for the eight-hole plate in the combined case with a $75 \%$ of volume reduction. The stress distribution shows that less stiff plates produce higher compressive stresses (in the plate-bone interface due to the bending load) at the fracture plane. Moreover, the neutral axis with the less stiff plates becomes closer to that of the bone's when compared with high stiff plates. In terms of plate mechanical stability (i.e. mechanical strength), the stresses among the least stiff fixation plates (75\% of volume reduction) are shown in Fig. 4. The maximum stresses occur on both four-hole and eight-hole designs with a combined load and $75 \%$ of volume reduction. Minimum values of the

Table 2 Maximum von Mises stresses on the bone at the fracture plane for all considered designs

\begin{tabular}{llll}
\hline Plate & $\begin{array}{l}\text { Volume } \\
\text { reduction } \\
(\%)\end{array}$ & \multicolumn{2}{l}{ Hole numbers } \\
\cline { 3 - 4 } \cline { 3 - 3 } \cline { 3 - 3 } Initial designs & N/A & 17.59 & 15.37 \\
Bending & 25 & 17.95 & 15.38 \\
& 45 & 19.93 & 15.93 \\
& 75 & 21.41 & 18.15 \\
Compression stress $(\mathrm{MPa})$ & 15.46 \\
& 25 & 17.94 & 15.58 \\
& 45 & 19.89 & 19.91 \\
Torsion & 75 & 20.79 & 15.73 \\
& 25 & 17.77 & 15.81 \\
& 45 & 19.92 & 18.25 \\
Combined & 25 & 20.03 & 15.40 \\
& 75 & 17.61 & 15.75 \\
& 45 & 17.88 & 21.07 \\
\hline
\end{tabular}

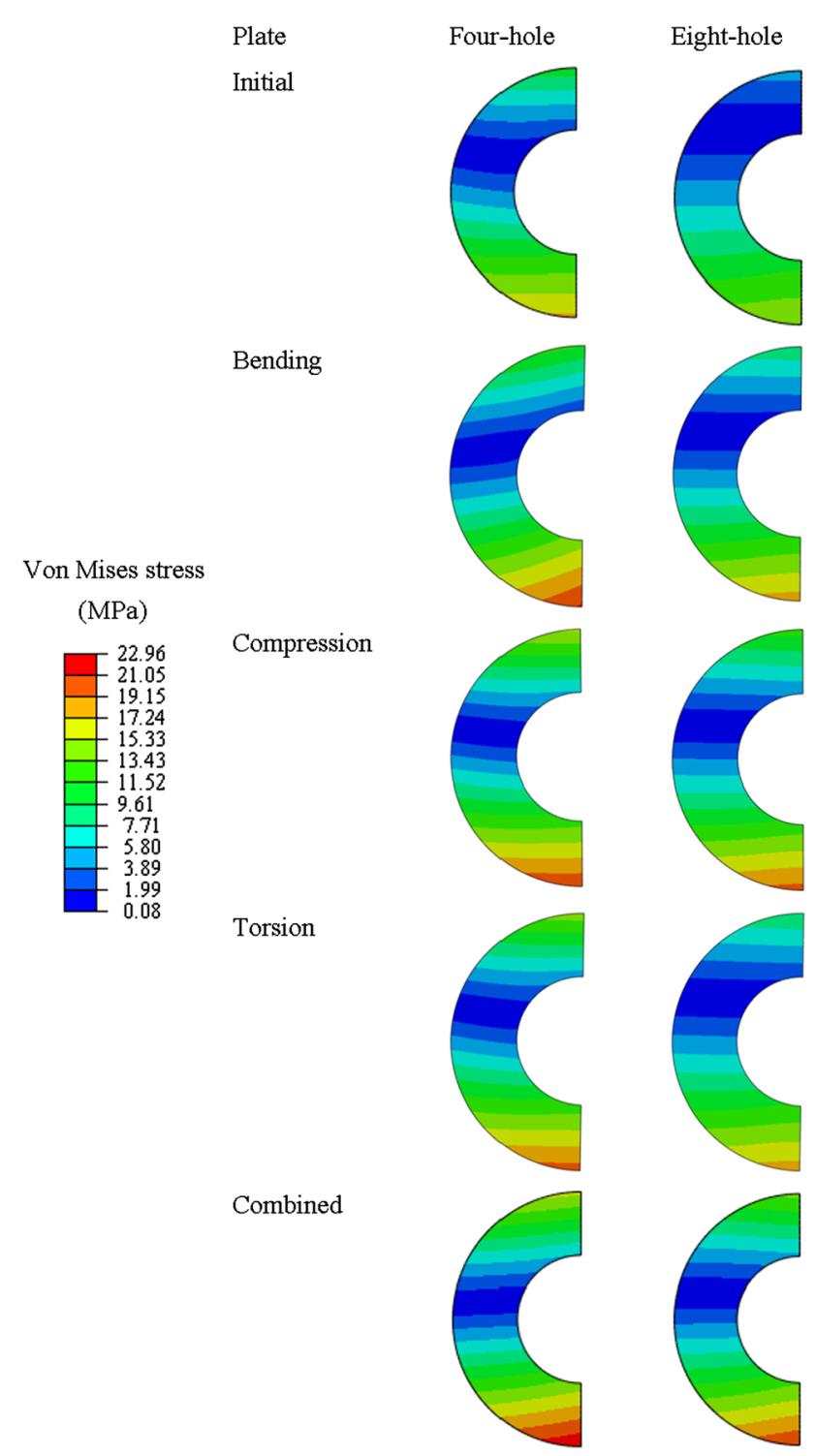

Fig. 3 von Mises stresses at the bone fracture plane resulted from the initial designs and all of the $75 \%$ volume reduction optimised plates

von Mises stresses for all plates occur for compression loads and $75 \%$ of volume reduction.

\section{Discussion and conclusions}

Results show that through topology optimisation it is possible to design less stiff fixation plates, resulting in higher loads being transferred to the bone fracture plane, whilst maintaining the plate's ability to withstand stresses. By considering a maximum of $75 \%$ of volume reduction for plates containing different screw holes, it is possible to increase the load transfer to up to $37 \%$ in comparison with the initial plates. This reduces stress shielding, and likely bone loss, to 
Fig. 4 Stress distribution on the optimised four- and eight-screw hole plates with $75 \%$ volume reduction and different loading conditions a bending, $\mathbf{b}$ compression, $\mathbf{c}$ torsion and $\mathbf{d}$ a combined load
Four-hole

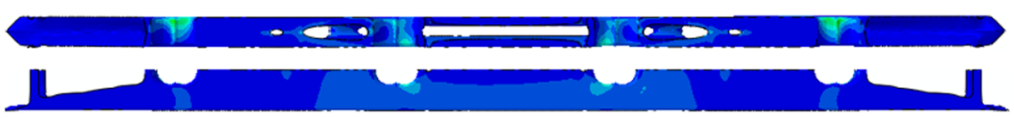

Eight-hole

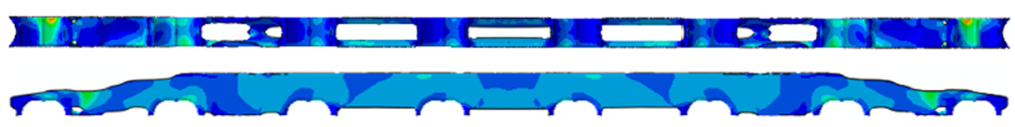

(a) Bending

Four-hole

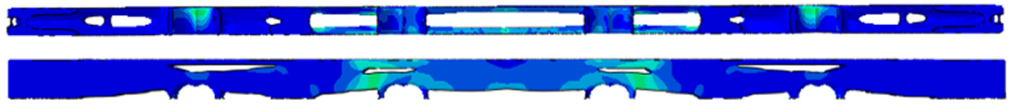

Eight-hole

Von Mises stress
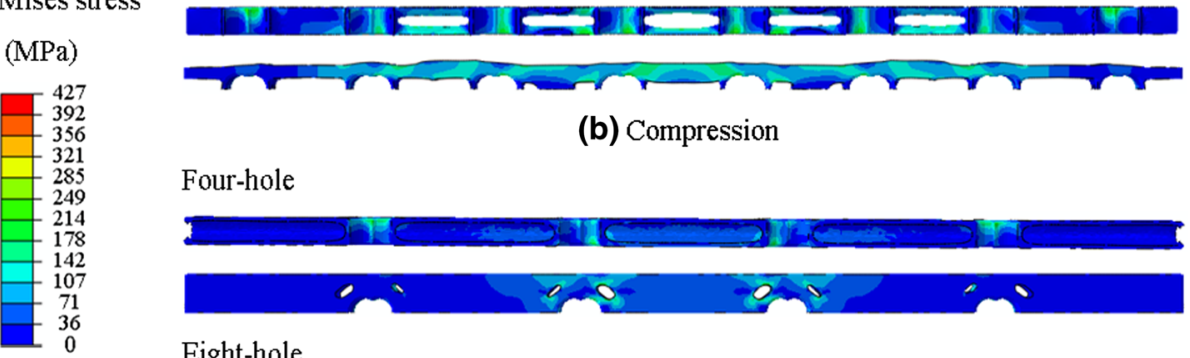

(b) Compression

Four-hole

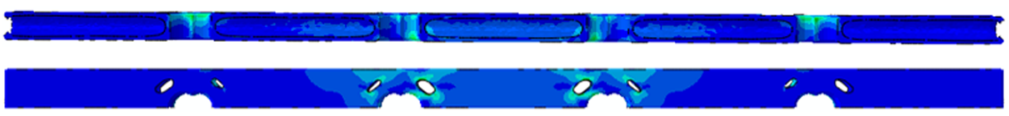

Eight-hole

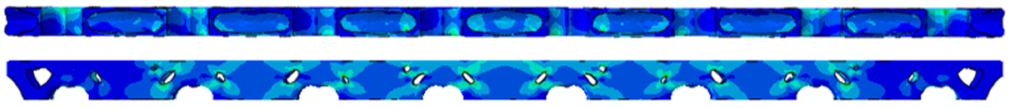

(c) Torsion

Four-hole

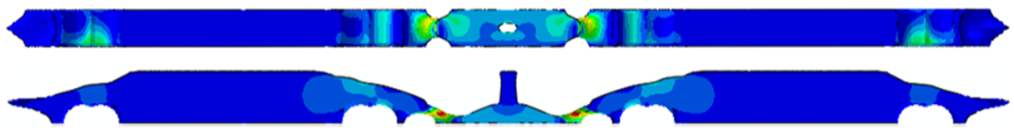

Eight-hole

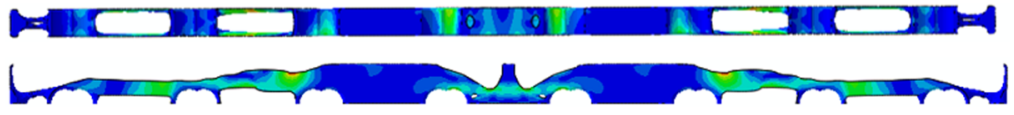

(d) Combined promoting secondary healing, that promotes callus formation and bone formation (Woo et al. 1977; Goodship and Kenwright 1985; Claes et al. 1997).

Maximum von Mises stresses were observed in plates optimised for combined loading conditions and $75 \%$ of volume reduction. This can be explained by stress concentrations induced by the plate design presenting thin features. However, as observed, the highest stresses are still $50 \%$ lower than the yield strength of the material, guaranteeing the plate mechanical stability.

For the four-hole plates, the best performance was observed for plates with $75 \%$ of volume reduction and optimised for bending loading conditions, which enable $22 \%$ of load transfer to the bone, presenting also low von Mises stresses (221 MPa). For the eight-hole plates, a maximum load transfer of $29 \%$ and $240 \mathrm{MPa}$ of von Mises stresses were observed for compression load optimised plates.

As shown, topology optimisation permits the design of less stiff and lightweight fixation plates, reducing the stress shielding effect, promoting load transfer to the bone and thus contributing to bone remodelling. However, further analysis is still required, considering for example a fracture gap and measuring the gap strains to correlate the resulted strains (i.e. relative or absolute stability) with the healing process (i.e. secondary or primary healing). Furthermore, screw threads were not considered in the simulation and their role on load transfer must be also considered. Although no critical failure was observed in the optimised designs, thin and sharp features were yet observed. Further post-processing design steps must be considered to address these features. 
Additional constraints must also be considered to allow further fabrication (e.g. thickness of internal features which might be difficult to produce using additive manufacturing).

Acknowledgements Authors are grateful for the support provided by the Saudi Arabian government, the Manchester University Foundation NHS Trust, Royal College of Surgeons of England, and the Portuguese Foundation for Science and Technology, through IDMEC, under LAETA, project UID/EMS/50022/2019.

\section{Compliance with ethical standards}

Conflict of interest The authors declare that they have no conflict of interest.

Open Access This article is distributed under the terms of the Creative Commons Attribution 4.0 International License (http://creativeco mmons.org/licenses/by/4.0/), which permits unrestricted use, distribution, and reproduction in any medium, provided you give appropriate credit to the original author(s) and the source, provide a link to the Creative Commons license, and indicate if changes were made.

\section{References}

Bendsøe M, Sigmund O (2004) Topology optimization: theory, methods, and applications. Springer, Berlin

Calignano F, Galati M, Iuliano L, Minetola P (2019) Design of additively manufactured structures for biomedical applications: a review of the additive manufacturing processes applied to the biomedical sector. J Healthc Eng 2019:9748212. https://doi. org/10.1155/2019/9748212

Chuah HG, Rahim IA, Yusof MI (2010) Topology optimisation of spinal interbody cage for reducing stress shielding effect. Comput Methods Biomech Biomed Eng 13:319-326. https://doi. org/10.1080/10255840903208189

Claes L, Augat P, Suger G, Wilke H (1997) Influence of size and stability of the osteotomy gap on the success of fracture healing. J Orthop Res 15:577-584. https://doi.org/10.1002/jor.1100150414

Elias C, Lima J, Valiev R, Meyers M (2008) Biomedical applications of titanium and its alloys. JOM 60:46-49. https://doi.org/10.1007/ s11837-008-0031-1

Fraldi M, Esposito L, Perrella G, Cutolo A, Cowin S (2010) Topological optimization in hip prosthesis design. Biomech Model Mechanobiol 9:389-402. https://doi.org/10.1007/s10237-009-0183-0

Galbusera F, Bertolazzi L, Balossino R, Dubini G (2009) Combined computational study of mechanical behaviour and drug delivery from a porous, hydroxyapatite-based bone graft. Biomech Model Mechanobiol 8:209-216. https://doi.org/10.1007/s1023 7-008-0132-3

Goodship A, Kenwright J (1985) The influence of induced micromovement upon the healing of experimental tibial fractures. J Bone Joint Surg Br 67-B:650-655. https://doi.org/10.1302/0301620x.67b4.4030869

Iqbal T, Wang L, Li D, Dong E, Fan H, Fu J, Hu C (2019) A general multi-objective topology optimization methodology developed for customized design of pelvic prostheses. Med Eng Phys 69:8-16. https://doi.org/10.1016/j.medengphy.2019.06.008
Kim S, Chang S, Son D (2011) Finite element analysis of the effect of bending stiffness and contact condition of composite bone plates with simple rectangular cross-section on the bio-mechanical behaviour of fractured long bones. Compos Part B Eng 42:17311738. https://doi.org/10.1016/j.compositesb.2011.03.001

Liu Y, Fan Y, Jiang X, Baur D (2017) A customized fixation plate with novel structure designed by topological optimization for mandibular angle fracture based on finite element analysis. BioMed Eng OnLine 16:1-17. https://doi.org/10.1186/s12938-017-0422-z

Murr LE (2016) Frontiers of 3D printing/additive manufacturing: from human organs to aircraft fabrication. J Mater Sci Technol 32:987995. https://doi.org/10.1016/j.jmst.2016.08.011

Parthasarathy J (2015) Additive manufacturing of medical devices. In: Srivatsan TS, Sudarshan TS (eds) Additive manufacturing innovations, advances, and applications. CRC Press, Boca Raton, pp 369-388

Prasad K, Bazaka O, Chua M, Rochford M, Fedrick L, Spoor J, Symes R, Tieppo M, Collins C, Cao A, Markwell D, Ostrikov K, Bazaka K (2017) Metallic biomaterials: current challenges and opportunities. Materials 10:884. https://doi.org/10.3390/ma10080884

Quental C, Fernandes PR, Monteiro J, Folgado J (2014) Bone remodelling of the scapula after a total shoulder arthroplasty. Biomech Model Mechanobiol 13:827-838. https://doi.org/10.1007/s1023 7-013-0537-5

Ramakrishna K, Sridhar I, Sivashakner S, Khong K, Ghista D (2004) Design of fracture fixation plate for necessary and sufficient bone stress shielding. JSME Int J Ser C 47:1086-1094. https://doi. org/10.1299/jsmec.47.1086

Ridzwan M, Shuib S, Hassan A, Shokri A, Ibrahim M (2006) Optimization in implant topology to reduce stress shielding problem. J Appl Sci 6:2768-2773. https://doi.org/10.3923/jas.2006.2768.2773

Ridzwan M, Shuib S, Hassan A, Shokri A, Ibrahim M (2007) Problem of stress shielding and improvement to the hip implant designs: a review. J Med Sci 7:460-467. https://doi.org/10.3923/ jms.2007.460.467

Santos B, Quental C, Folgado J, Sarmento M, Monteiro J (2018) Bone remodelling of the humerus after a resurfacing and a stemless shoulder arthroplasty. Clin Biomech 59:78-84. https://doi. org/10.1016/j.clinbiomech.2018.09.009

Saravana KG, George S (2017) Optimization of custom cementless stem using finite element analysis and elastic modulus distribution for reducing stress-shielding effect. Proc Inst Mech Eng Part H J Eng Med 231:149-159. https://doi.org/10.1177/0954411916 686125

Wehner T, Claes L, Simon U (2009) Internal loads in the human tibia during gait. Clin Biomech 24:299-302. https://doi.org/10.1016/j. clinbiomech.2008.12.007

Woo S, Simon B, Akeson W, McCarty M (1977) An interdisciplinary approach to evaluate the effect of internal fixation plate on long bone remodeling. J Biomech 10:87-95. https://doi. org/10.1016/0021-9290(77)90072-0

Yuan L, Ding S, Wen C (2019) Additive manufacturing technology for porous metal implant applications and triple minimal surface structures: a review. Bioact Mater 4:56-70. https://doi. org/10.1016/j.bioactmat.2018.12.003

Publisher's Note Springer Nature remains neutral with regard to jurisdictional claims in published maps and institutional affiliations. 